\title{
5-FITC-labeled Colon-Heptapeptide
}

National Cancer Institute

\section{Source}

National Cancer Institute. 5-FITC-labeled Colon-Heptapeptide. NCI Thesaurus. Code C116354.

A radioconjug ate consisting of a 7 amino acid peptide sequence, KCCFPAQ, that specifically targets human colon cancer and labeled, via the linker, GGGSK, with the fluorescent dye, fluorescein isothiocyanate (5-FITC), with potential imaging activity. Following spray application to the colon wall during colonoscopy in areas that look abnormal, the colon heptapeptide moiety of 5-FITC-labeled colon-heptapeptide specifically targets and binds to a cell surface target overexpressed on pre-cancerous or cancerous colon cells. Upon internalization, the FITC moiety allows for fluorescent imaging and the area of interest for biopsies can then be visualized. 